\title{
A Simple and Sensitive One-Dimensional NMR Technique for Correlation of Proton and Carbon Chemical Shifts
}

\author{
SUSANTA K. SARKAR AND AD BAX \\ Laboratory of Chemical Physics, National Institute of Arthritis, Diabetes and Digestive \\ and Kidney Diseases, National Institutes of Health, Bethesda, Maryland 20205
}

Received June 4, 1984; revised October 23, 1984

A slightly modified version of the well-known selective population transfer (SPT) experiment $(1-5)$ is described that is very easy to use and correlates ${ }^{1} \mathrm{H}$ and ${ }^{13} \mathrm{C}$ or ${ }^{15} \mathrm{~N}$ chemical shifts with high sensitivity and accuracy. Although the changes with the original experiment (1) are relatively small, they are helpful for reliable and convenient use of the experiment.

Two-dimensional heteronuclear chemical-shift correlation (6-10) has proven to be a powerful tool for the assignment of ${ }^{13} \mathrm{C}$ spectra. However, in practice, sensitivity of the two-dimensional experiment is at best about a factor of three lower $(10)$ than that of a regular proton-decoupled ${ }^{13} \mathrm{C}$ spectrum. Moreover, large data matrices are usually required in this type of $2 \mathrm{D}$ experiment and minimum data acquisition plus processing time often exceeds one hour.

Recently, there has been a renewed interest in alternative one-dimensional experiments that provide essentially the same information as the $2 \mathrm{D}$ experiment by transfer of magnetization from a preselected proton to its coupled ${ }^{13} \mathrm{C}$ nucleus (11-14), or by suppression of the resonance of a ${ }^{13} \mathrm{C}$ that is coupled to a preselected proton (15). Those sequences are all very elegant, but are for most purposes unnecessarily complicated and suffer more from relaxation effects than necessary. Furthermore, in some of those experiments confusion may arise about whether the magnetization has been transferred from the high-field carbon satellite of one proton or from the low-field satellite of another proton that resonates at a frequency $J_{\mathrm{CH}}$ lower than the first proton.

In the SPT experiment (Fig. 1), a soft ${ }^{1} \mathrm{H} 180^{\circ}$ pulse $\left(\gamma \mathrm{H}_{2} / 2 \pi=20 \mathrm{~Hz}\right.$ ) selectively inverts proton resonances of either the low-field or the high-field ${ }^{13} \mathrm{C}$ satellite. For a methine group, this changes the populations of the energy levels in such a way that the two ${ }^{13} \mathrm{C}$ doublet components change in intensity by a factor of \pm 4 compared with their thermal equilibrium values (without NOE). The theory of this phenomenon has been described in the original literature (1-5), and will not be repeated here. Broadband proton decoupling cannot be started immediately after the ${ }^{13} \mathrm{C}$ detection pulse, as this would cause mutual cancellation of the antiphase ${ }^{13} \mathrm{C}$ doublet components. However, a delay $1 /\left(2 I_{\mathrm{CH}}\right)$ for methine groups, or $1 /\left(4 . I_{\mathrm{CH}}\right)$ for methylene and methyl groups inserted before decoupling is started (Fig. 1) will prevent signal cancellation and allow proton-decoupled ${ }^{13} \mathrm{C}$ spectra to be recorded 


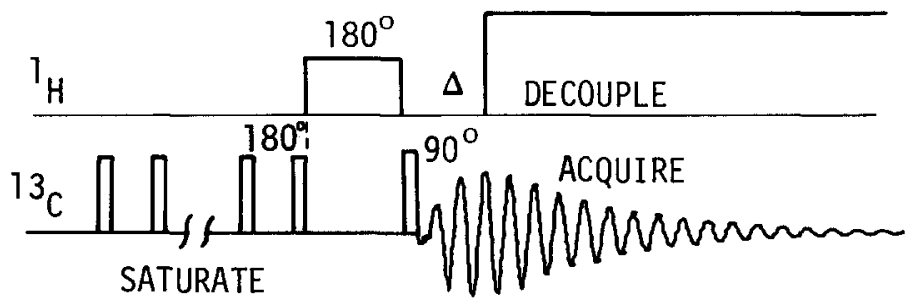

FIG. 1. Pulse sequence of the decoupled SPT experiment. Saturation of the ${ }^{13} \mathrm{C}$ signal is obtained by the application of a number $(>10)$ of $180^{\circ}{ }^{13} \mathrm{C}$ pulses spaced by 2.2 times the width of the selective $180^{\circ}$ ' $\mathrm{H}$ pulse. The radiofrequency field strength $\left(\gamma \mathrm{H}_{2} / 2 \pi\right)$ of the soft proton $180^{\circ}$ pulse is on the order of 20 $\mathrm{Hz}$ (pulse width $25 \mathrm{~ms}$ ). Data acquisition is started immediately after the $90^{\circ}$ observe pulse, and broadband decoupling is switched on a time, $\Delta$, later. The duration of $\Delta$ is set to $1 /\left(2 J_{\mathrm{CH}}\right)$ for methine resonances and to $1 /\left(4 J_{\mathrm{CH}}\right)$ for methylene and methyl groups.

$(16,17)$. Note that in the case where the ${ }^{13} \mathrm{C}$ satellite of one of the two nonequivalent protons of a geminal pair is inverted, only a factor of two enhancement in the decoupled spectrum is obtained.

Because transverse ${ }^{13} \mathrm{C}$ magnetization rotates during the time, $\Delta$, under the influence of scalar coupling and chemical shift, a large frequency-dependent phase error of the decoupled SPT spectrum would be induced if acquisition is started at time, $\Delta$, after the ${ }^{13} \mathrm{C}$ detection pulse. The simplest way around this is to start data acquisition immediately after the observe pulse, while the decoupler is switched on at time, $\Delta(18) .{ }^{13} \mathrm{C}$ signals due to SPT transfer will be either $+90^{\circ}$ or $-90^{\circ}$ out of phase relative to signals recorded in a conventional "one-pulse" ${ }^{13} \mathrm{C}$ spectrum, depending on whether the high-field or the low-field ${ }^{13} \mathrm{C}$ satellite has been inverted. A phase correction of $+90^{\circ}$ will phase those resonances to negative and positive absorption mode, respectively. A small baseline distortion will be induced by the fact that during the short time, $\Delta$, no proton decoupling was applied. To suppress ${ }^{13} \mathrm{C}$ signals that are not due to SPT transfer, a number of ${ }^{13} \mathrm{C} 180^{\circ}$ saturation pulses are applied prior to the selective $180^{\circ}{ }^{1} \mathrm{H}$ pulse (Fig. 1). Optimum suppression is obtained if the spacing between the $180^{\circ}{ }^{13} \mathrm{C}$ pulses is about 2.2 times the duration of the selective ${ }^{1} \mathrm{H} 180^{\circ}$ pulse. A suppression factor larger than 100 is easily obtained.

Figure 2 demonstrates the effectiveness of the method for a sample of chrysene, a potent carcinogen. A $16 \mathrm{~m} M$ solution in $\mathrm{CDCl}_{3}$ in a $10 \mathrm{~mm}$ sample tube is used. The $500 \mathrm{MHz}$ proton spectrum is easily assigned via a COSY experiment. The doublets of protons $\mathrm{H}-4$ and $\mathrm{H}-5$ are partially overlapping as their difference in chemical shift is only $0.016 \mathrm{ppm}$, and provide a challenging test for the accuracy of the SPT method. Figure $2 \mathrm{~b}$ shows the regular NOE enhanced ${ }^{13} \mathrm{C}$ spectrum of the protonated aromatic carbons, obtained from 200 accumulations (12 min). Aromatic $\mathrm{CH}$ couplings are approximately $160 \mathrm{~Hz}$, and in the SPT experiments the selective $180^{\circ}$ proton pulse (duration $27 \mathrm{~ms}$ ) is applied $80 \mathrm{~Hz}$ downfield from the respective proton chemical shifts. Figure $2 \mathrm{c}$ shows the SPT spectrum for transfer from the downfield satellite of $\mathrm{H}-3$ and clearly shows a positive carbon resonance for C-3. As the selective proton pulse also affects the high-field satellite of $\mathrm{H}-4$ (which resonates $12 \mathrm{~Hz}$ downfield from the low-field satellite of $\mathrm{H}-3$ ), a negative signal for $\mathrm{C}-4$ is 



C
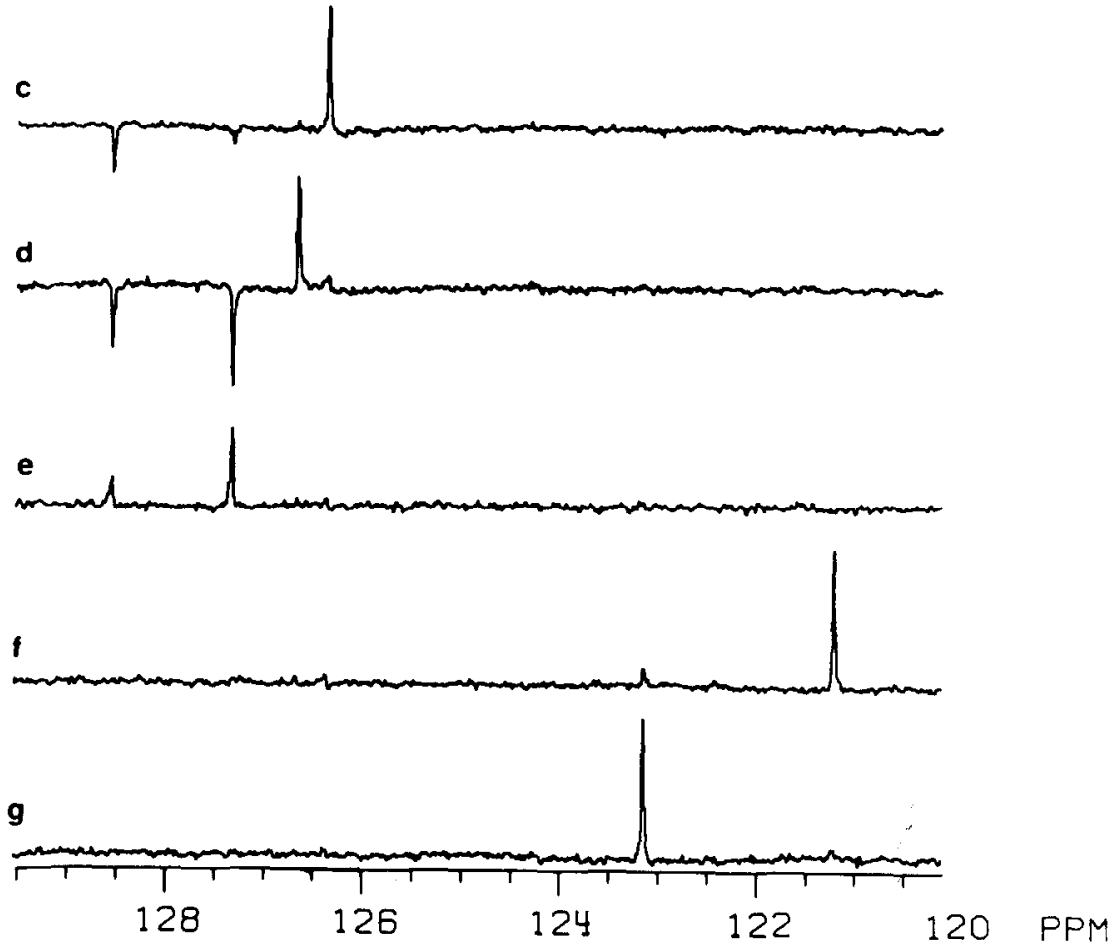

FIG. 2. (a) $500 \mathrm{MHz}$ proton spectrum of a $16 \mathrm{mM}$ solution of chrysene in $\mathrm{CDCl}_{3}$, recorded using the decoupler coil of a $10 \mathrm{~mm}$ broadband probe on a NT-500 spectrometer. (b) Conventional protondecoupled ${ }^{13} \mathrm{C}$ spectrum obtained from 200 scans ( $12 \mathrm{~min}$ ). (c)-(g) SPT spectra obtained by transfer from the low-field ${ }^{13} \mathrm{C}$ satellites of $\mathrm{H}-3, \mathrm{H}-2, \mathrm{H}-5, \mathrm{II}-6$, and $\mathrm{H}-1$, respectively. Negative signals in those spectra result from SPT transfer of the high-field satellites of $\mathrm{H}-4$ and $\mathrm{H}-5$ which are also affected by the soft $180^{\circ}$ pulses applied to the downfield satellites of $\mathrm{H}-3$ and H-2. Each SPT spectrum is the result of 160 scans (10 $\mathrm{min}$ ). 
detected. Similarly, Fig. 2d shows the SPT spectrum from the lower field satellite of $\mathrm{H}-2$ (positive resonance $\mathrm{C}-2$ ), in which the selective ${ }^{1} \mathrm{H}$ pulse also affects the highfield satellite of $\mathrm{H}-5$, and yields a negative signal for C-5. Figure $2 \mathrm{e}$ shows the SPT spectrum obtained by applying the selective $180^{\circ}$ pulse $85 \mathrm{~Hz}$ downfield from the chemical shift of $\mathrm{H}-5$, and clearly differentiates between C-5 (high intensity) and C4 (low intensity). Finally, Figs. $2 \mathrm{f}$ and $\mathrm{g}$ show the transfer spectra for protons H-6 and H-1. Each SPT spectrum is the result of 160 accumulations (10 $\mathrm{min})$.

The simplicity, high sensitivity, and high resolution of the decoupled SPT experiment make it very attractive for use in cases where only a limited number of ${ }^{13} \mathrm{C}$ resonances have to be correlated. Of course, distinction between methyl, methylene, and methine resonances is easily possible by variation of the delay, $\Delta$ $(16,19)$. A drawback of the SPT experiment is the required knowledge of the approximate value of the ${ }^{1} \mathrm{H}-{ }^{13} \mathrm{C}$ coupling constant. Since one-bond $\mathrm{C}-\mathrm{H}$ couplings have been well studied (20) this usually does not present serious problems. The experiment is, of course, not limited to the detection of ${ }^{13} \mathrm{C}$, and can be applied directly to a number of other interesting nuclei.

\section{ACKNOWLEDGMENTS}

The authors thank Dr. E. D. Becker and Dr. J. A. Ferretti for many stimulating discussions and Laura Lerner for useful suggestions during the preparation of the manuscript.

\section{REFERENCES}

1. K. G. R. PAChler AND P. L. Wessels, J. Magn. Reson. 12, 337 (1973).

2. S. Sørensen, R. S. HANSEN, AND H. J. JAKobSEN, J. Magn. Reson. 14, 243 (1974).

3. H. J. JakobSEN AND W. S. BreY, J. Am. Chem. Soc. 101, 774 (1978).

4. K. G. R. PAChler and P. I. Wessels, J. Magn. Reson. 28, 53 (1977).

5. H. J. JAKobsen, S. A. Linde, AND S. Sørensen, J. Magn. Reson. 15, 385 (1974).

6. A. A. Maudsley and R. R. ERnst, Chem. Phys. Lett. 50, 368 (1977).

7. G. Bodenhausen and R. Freeman, J. Magn. Reson. 28, 471 (1977).

8. A. A. Maudsley, L. Muller, AND R. R. ERnst, J. Magn. Reson. 28, 463 (1977).

9. A. BAX, "Two-Dimensional Nuclear Magnetic Resonance in Liquids," Chap. 2, Reidel, Boston, 1982.

10. A. BaX AND G. A. MorRIS, J. Magn. Reson. 42, 501 (1981).

11. J. Brondeau AND D. CANET, J. Magn. Reson. 47, 419 (1982).

12. D. M. Doddrell, W. Brooks, J. Field, AND R. Lynden-Bell, J. Am. Chem. Soc. 105, 6973 (1983).

13. H. J. JAKobSEn, H. BILdSOE, S. Donstrop, AND O. W. SørEnSEN, J. Magn. Reson. 57,324 (1984).

14. D. M. Doddrell, W. BROOKS, J. FIELD, AND R. M. Lynden-Bell, J. Magn. Reson. 59, 384 (1984).

15. D. D. Davis, D. H. Live, W. C. Agosta, and D. Cowburn, J. Magn. Reson. 53, 350 (1983).

16. D. P. Burum AND R. R. ERnSt, J. Magn. Reson. 39, 163 (1980).

17. H. J. Jakobsen, P. J. Kanyha, AND W. S. Brey, J. Magn. Reson. 54, 134 (1983).

18. A. BAX AND S. K. SARKaR, J. Magn. Reson. 60, 170 (1984).

19. D. M. Doddrell and D. T. PEGG, J. Am. Chem. Soc. 102, 6388 (1980).

20. P. E. Hansen, Prog. Nucl. Magn. Reson. Spectrosc. 14, 175 (1981), and references therein. 